\title{
Effect of Cod Residual Protein Supplementation on Markers of Glucose Regulation in Lean Adults: A Randomized Double-Blind Study
}

\author{
Iselin Vildmyren ${ }^{1,2, *}$, Alfred Halstensen ${ }^{2,3}$, Adrian McCann ${ }^{4}{ }^{\circledR}$, Øivind Midttun ${ }^{4}$, \\ Per Magne Ueland ${ }^{4}$, Åge Oterhals ${ }^{5}(-)$ and Oddrun Anita Gudbrandsen ${ }^{1}(\mathbb{C})$ \\ 1 Dietary Protein Research Group, Department of Clinical Medicine, University of Bergen, 5021 Bergen, \\ Norway; nkjgu@uib.no \\ 2 K. Halstensen AS, P.O. Box 103, 5399 Bekkjarvik, Norway; alfred.halstensen@uib.no \\ 3 Department of Clinical Science, University of Bergen, 5021 Bergen, Norway \\ 4 Bevital AS, Jonas Lies veg 87, 5021 Bergen, Norway; adrian.mccann@bevital.no (A.M.); \\ nkjbm@uib.no (Ø.M.); per.ueland@ikb.uib.no (P.M.U.) \\ 5 Nofima, P.B. 1425 Oasen, 5844 Bergen, Norway; aage.oterhals@nofima.no \\ * Correspondence: iselin.vildmyren@uib.no; Tel.: +47-5597-5553
}

Received: 16 April 2020; Accepted: 13 May 2020; Published: 16 May 2020

\begin{abstract}
Large quantities of protein-rich cod residuals, which are currently discarded, could be utilized for human consumption. Although fish fillet intake is related to beneficial health effects, little is known about the potential health effects of consuming cod residual protein powder. Fifty lean adults were randomized to consume capsules with $8.1 \mathrm{~g} /$ day of cod residual protein (Cod-RP) or placebo capsules (Control group) for eight weeks, in this randomized, double-blind study. The intervention was completed by 40 participants. Fasting glucose and insulin concentrations were unaffected by Cod-RP supplementation, whereas plasma concentrations of $\alpha$-hydroxybutyrate, $\beta$-hydroxybutyrate and acetoacetate all were decreased compared with the Control group. Trimethylamine $\mathrm{N}$-oxide concentration in plasma and urine were increased in the Cod-RP group compared with the Control group. To conclude, the reduction in these potential early markers of impaired glucose metabolism following Cod-RP supplementation may indicate beneficial glucoregulatory effects of cod residual proteins. Trimethylamine N-oxide appears to be an appropriate biomarker of cod residual protein intake in lean adults.
\end{abstract}

Keywords: dietary supplements; fish protein; marine protein; hydroxybutyrate; TMAO; biomarkers

\section{Introduction}

Fish intake is associated with beneficial effects on risk factors for type 2 diabetes and cardiovascular disease [1-7], and these effects have mainly been attributed to the content of long-chain $n-3$ polyunsaturated fatty acids (n-3 PUFA) in fish [8]. Although underlying mechanisms are still unclear, several studies have shown that lean fish may also improve insulin sensitivity and glucose regulation, despite containing very low amounts of long-chain n-3 PUFA [9-15]. Small alterations in glucose regulation may be difficult to identify in short-term dietary intervention studies among healthy individuals. Therefore, other markers of glucose regulation that may be more sensitive to detecting small regulatory changes, other than fasting glucose and insulin concentrations, should be explored. Studies have shown that metabolites of fatty acid $\beta$-oxidation and ketogenic amino acid catabolism, such as $\alpha$-hydroxybutyrate ( $\alpha$-HB), $\beta$-hydroxybutyrate $(\beta-\mathrm{HB})$ and acetoacetate (AcAc), may reflect early changes in glucose regulation [16-19]. 
People in the western world mostly consume the fish fillet, and not the whole fish or the residuals. The residuals from fillet production consist of head, backbone, skin, entrails and trimmings, which contain up to $70 \%$ protein when dried [20]. Currently, large quantities of residuals from cod are discarded, and the rest is mostly utilized for non-food purposes, such as feed ingredients for agriculture and aquaculture. To our knowledge, only two clinical studies on cod residual protein intake have been conducted so far, and findings suggest that cod residual protein supplementation may beneficially affect glucose regulation and lipid metabolism [14,21]. Thus, further studies investigating potential health effects of cod residual protein for human consumption should be undertaken.

The assessment of dietary compliance is vital in nutrition intervention studies, and biomarkers reflecting dietary intake would be especially useful for evaluating intervention efficacy [22]. Higher concentrations of creatine, 1-methylhistidine (1-MeHis), 3-methylhistidine (3-MeHis) [23,24] and trimethylamine $\mathrm{N}$-oxide (TMAO) [23,25-31] have been associated with cod fillet intake in both rats and humans. These observations highlight the potential use of these compounds as biomarkers of cod protein intake from residuals in supplement studies.

The current study aimed to investigate the effects of cod residual protein supplementation on circulating markers related to glucose regulation, and potential biomarkers of cod residual protein intake. We hypothesized that eight weeks of $8.1 \mathrm{~g}$ cod residual protein (Cod-RP) per day would decrease concentrations of circulating markers of glucose regulation, and increase concentrations of potential plasma and urine biomarkers of cod residual protein intake in lean adults. Cod-RP supplementation caused reduced fasting plasma concentrations of $\alpha$-hydroxybutyrate, $\beta$-hydroxybutyrate and acetoacetate, compared with the Control group. Increased trimethylamine $\mathrm{N}$-oxide concentrations in plasma and urine suggest it could function as a biomarker of cod residual protein intake in lean adults.

\section{Materials and Methods}

\subsection{Participants and Ethics}

The study population consisted of healthy, lean adults. The eligibility criteria included BMI $\geq$ $18.5 \mathrm{~kg} / \mathrm{m}^{2}$ with body fat percentage $12-35 \%$ for women and $5-25 \%$ for men, stable body weight $(<5 \mathrm{~kg}$ variation in 3 months), fasting blood glucose $<7.0$ millimoles/L, and age $20-55$ years. Exclusion criteria included disorders affecting kidney, heart, intestinal function, or insulin secretion, use of prescription medications for high cholesterol, seafood intake $>200 \mathrm{~g} /$ week, allergies towards seafood, gluten or milk, and use of dietary supplements. Pregnant and lactating women were not included in the study.

The participants provided written informed consent prior to study enrolment. The Regional Ethics Committee of Western Norway approved the study (approval no.: 2015/75). The study was conducted in accordance with the Declaration of Helsinki and is registered at clinicaltrials.gov (NCT03538834).

\subsection{Study Design, Intervention and Protocol}

This double-blind, randomized intervention study was conducted at the University of Bergen (Bergen, Norway). In brief, 50 participants were stratified according to gender and age, and randomized to one of two groups, consuming 27 capsules with a total of $8.1 \mathrm{~g}$ of cod residual protein (Cod-RP group), or 27 placebo capsules (Control group) daily for eight weeks. Participants were instructed to maintain their dietary and physical activity routines unchanged during the eight week intervention period. The participants attended two study visits: at baseline and after eight weeks. The study visits were performed after an overnight fast $(>10 \mathrm{~h}$ ) without consuming drink (except for water), food, medications or tobacco. Participants were instructed to not consume alcohol or engage in intensive physical activity for $24 \mathrm{~h}$ before the study visits.

The participants' height was measured using a stadiometer (Telescopic Measuring Rod MZ10023-3, ADE, Hamburg, Germany), and body composition was measured using a bioelectrical impedance analyzer (InBody 720, Seoul, Korea). Participants provided urine samples in a fasted state. Fasting blood samples for whole blood and isolation of plasma were collected in Vacuette K2EDTA (Greiner 
Bio-One GmbH, Kremsmünster, Austria) and Vacutainer SST II Advanced Plus (Becton, Dickinson and Company, Franklin Lakes, NJ, USA) for isolation of serum. Postprandial blood samples were collected every $30 \mathrm{~min}$ for $2 \mathrm{~h}$ after the participants consumed a drink containing $75 \mathrm{~g}$ glucose (Dextrose from SunVita AS, Nyborg, Norway) and $35 \mathrm{~g}$ whey protein (Proteinfabrikken AS, Stokke, Norway) mixed with $200 \mathrm{~mL}$ of water, as a modified oral glucose tolerance test (OGTT).

\subsection{Production and Analyses of Intervention Capsules}

Northeast Atlantic cod (Gadus morhua) residuals from fillet production, consisting of head, backbone, skin, entrails and trimmings were processed on-board the factory trawler Granit (Halstensen Granit AS, Bekkjarvik, Norway). The cod residuals were ground, heat treated at $90{ }^{\circ} \mathrm{C}$, pressed and dried on-board the trawler, and the solid phase and liquid phase was dried and mixed at Seagarden AS (Karmøy, Norway). All capsules for the study were produced at Pharmatech AS (Fredrikstad, Norway). A detailed description of the production of intervention capsules is described elsewhere [21] and the contents of the capsules are presented in Table 1.

Table 1. Capsule content.

\begin{tabular}{ccc}
\hline Per Capsule & Cod-RP & Control \\
\hline Cod residual powder ${ }^{*}(\mathrm{mg})$ & 474 & 0 \\
Microcrystalline cellulose $(\mathrm{mg})_{\text {Magnesium stearate }(\mathrm{mg})}$ & 42 & 454 \\
Silica $(\mathrm{mg})$ & 5.3 & 4.6 \\
Total capsule weight $(\mathrm{mg})$ & 5.3 & 4.6 \\
Energy $^{\dagger}(\mathrm{kcal})$ & 527 & 463 \\
${ }^{*}$ Crude protein content $64 \%$, total fat content $8.6 \%$. & \\
protein powder.
\end{tabular}

Trimethylamine N-oxide (TMAO) content in the cod residual powder and placebo capsules was determined using the micro-diffusion assay described by Conway and Byrne [32] and anserine was measured by High Performance Liquid Chromatographyusing the Waters Pico-Tag method [33]. The contents of TMAO, anserine, crude protein, total fat and microorganisms were measured by Nofima BioLab (Bergen, Norway). Contents of the heavy metals cadmium and mercury were analyzed by Eurofins AS (Ålesund, Norway).

\subsection{Analyses of Biological Samples}

Glucose concentration in serum, $\mathrm{HbA1c}$ (glycated haemoglobin) concentration in whole blood and concentrations of creatinine and albumin in urine were analyzed on the Cobas c 111 system (Roche Diagnostics GmbH, Mannheim, Germany) using the GLUC2, A1C-3 (with A1CD2 hemolyzing reagent) and CREP2 kits from Roche Diagnostics for the c111 system. Serum insulin concentration was analyzed using the EIA-2935 ELISA kit (DRG Instruments GmbH, Marburg, Germany).

Plasma concentrations of $\alpha-\mathrm{HB}, \beta-\mathrm{HB}, \mathrm{AcAc}$, and plasma and urine concentration of 1-methylhistidine (1-MeHis, $\pi$-methyl-histidine), 3-methylhistidine (3-MeHis, $\tau$-methyl-histidine), creatine, trimethylamine N-oxide (TMAO) and creatinine were measured by Bevital AS (http://www.bevital.no) using gas chromatography and liquid chromatography with tandem mass spectrometry [34,35]. $\alpha-\mathrm{HB}, \beta-\mathrm{HB}$, AcAc, 1-MeHis, 3-MeHis and TMAO were analyzed by adding the analytes and isotope-labelled internal standards to existing assays [34,35].

\subsection{Outcomes}

The primary outcome was changes in circulating markers related to glucose regulation in lean adults after eight weeks of cod residual protein supplementation. The secondary outcome was changes in potential urine and plasma biomarkers of cod residual protein intake. 


\subsection{Sample Size}

Power analysis was not feasible for the original study, which was designed as a pilot study and is the first to investigate effects of cod residuals on circulating markers of lipid metabolism in lean adults [21]. Therefore, no estimation of sample size for the current measurements was conducted prior to the study.

\subsection{Statistical Analyses}

Normality of data was assessed by the Shapiro-Wilk test, histograms and QQ plots. Variables that were not normally distributed underwent log-transformation before parametric statistical tests were performed. The Paired samples $T$-test was used to detect baseline to eight week changes within groups, and the Independent samples $T$-test was used to compare baseline to eight weekchanges between the two experimental groups. The level of statistical significance was set to $p<0.05$. SPSS Statistics version 25 (IBM Corp. IBM SPSS for Windows, Armonk, NY, USA) was used for statistical analyses.

\section{Results}

\subsection{Participant Characteristics}

Of the fifty participants initially included, forty participants (18 women and 22 men) completed the eight weeks intervention (Figure 1). Four participants withdrew from the study, and six participants were excluded from further analyses due to non-compliance $(n=5)$ or disease $(n=1)$. Non-compliance was defined as not taking the study supplements, consuming $>200 \mathrm{~g} /$ week of seafood, and changes in habitual dietary intake or physical activity. Three participants were excluded from the OGTT due to difficulties drawing blood. Age, body weight, BMI, body fat percentage, body muscle percentage, concentrations of fasting glucose, insulin, $\alpha-\mathrm{HB}, \beta-\mathrm{HB}, \mathrm{AcAc}$ and cigarette or snus use were similar between the two groups at baseline (Table 2). The concentrations of whole blood $\mathrm{HbA1c}$, plasma creatinine and urine albumin (relative to creatinine) were within normal range in all participants at baseline: for $\mathrm{HbA1c}$, $<42 \mathrm{mmol} / \mathrm{mol}$ International Federation of Clinical Chemistry and Laboratory Medicine (IFCC); for creatinine, $45-90 \mu \mathrm{mol} / \mathrm{L}$ in women and $60-105 \mu \mathrm{mol} / \mathrm{L}$ in men; and for albumin, $0-2.5 \mathrm{mg} / \mathrm{mmol}$. Concentrations of whole blood $\mathrm{HbA1c}$, plasma creatinine and urine albumin were unchanged after eight weeks intervention (data not presented). Estimated dietary energy and macronutrient intake did not differ between the groups from baseline to eight weeks, as previously presented [21].

Table 2. Participant characteristics at baseline.

\begin{tabular}{cccc}
\hline & Cod-RP $(\boldsymbol{n = 1 9 )}$ & Control $(\boldsymbol{n}=\mathbf{2 1})$ & $p$ \\
\hline Women/Men & Mean \pm SD & Mean \pm SD & \\
Age $($ years $)$ & $7 / 12$ & $11 / 10$ & 0.36 \\
Body weight $(\mathrm{kg})$ & $28.0 \pm 6.9$ & $30.5 \pm 7.2$ & 0.28 \\
BMI $\left(\mathrm{kg} / \mathrm{m}^{2}\right)$ & $77.0 \pm 16.0$ & $73.1 \pm 11.5$ & 0.39 \\
Body fat $(\%)$ & $24.8 \pm 2.8$ & $23.8 \pm 2.3$ & 0.25 \\
Body muscle $(\%)$ & $19.7 \pm 6.8$ & $19.4 \pm 6.7$ & 0.89 \\
Whole blood HbA1c $(\mathrm{mmol} / \mathrm{mol})$ & $45.4 \pm 4.7$ & $45.4 \pm 4.4$ & 0.95 \\
Plasma creatinine $(\mu \mathrm{mol} / \mathrm{L})$ & $32.4 \pm 2.2$ & $31.5 \pm 2.0$ & 0.23 \\
Urine albumin $(\mathrm{mg} / \mathrm{mmol} \mathrm{creatinine})$ & $80.1 \pm 13.1$ & $77.2 \pm 11.1$ & 0.46 \\
Serum glucose $(\mathrm{mmol} / \mathrm{L})$ & $0.7 \pm 0.5$ & $1.0 \pm 0.9$ & 0.23 \\
Serum insulin $(\mathrm{pmol} / \mathrm{L})$ & $5.1 \pm 0.4$ & $4.9 \pm 0.3$ & 0.21 \\
Plasma $\alpha-\mathrm{HB}(\mu \mathrm{mol} / \mathrm{L})$ & $68.1 \pm 32.8$ & $56.3 \pm 25.9$ & 0.55 \\
Plasma $\beta-H B(\mu \mathrm{mol} / \mathrm{L})$ & $44.2 \pm 19.3$ & $35.1 \pm 17.0$ & 0.80 \\
Plasma AcAc $(\mu \mathrm{mol} / \mathrm{L})$ & $143 \pm 156$ & $102 \pm 108$ & 0.34 \\
Cigarette/snus $*(n)$ & $76.5 \pm 67.0$ & $65.1 \pm 52.1$ & 0.86 \\
\hline
\end{tabular}

Values are presented as mean \pm standard deviation. Groups were compared at baseline using independent samples $T$-test for continuous data and Pearson's Chi-square test for categorical data. ${ }^{*}$ Snus is a Scandinavian tobacco substance which is placed under the upper lip. Cod-RP, cod residual protein powder; BMI, body mass index; HbA1c, glycated haemoglobin; $\alpha$-HB, $\alpha$-hydroxybutyrate; $\beta$-HB, $\beta$-hydroxybutyrate; AcAc, acetoacetate. 


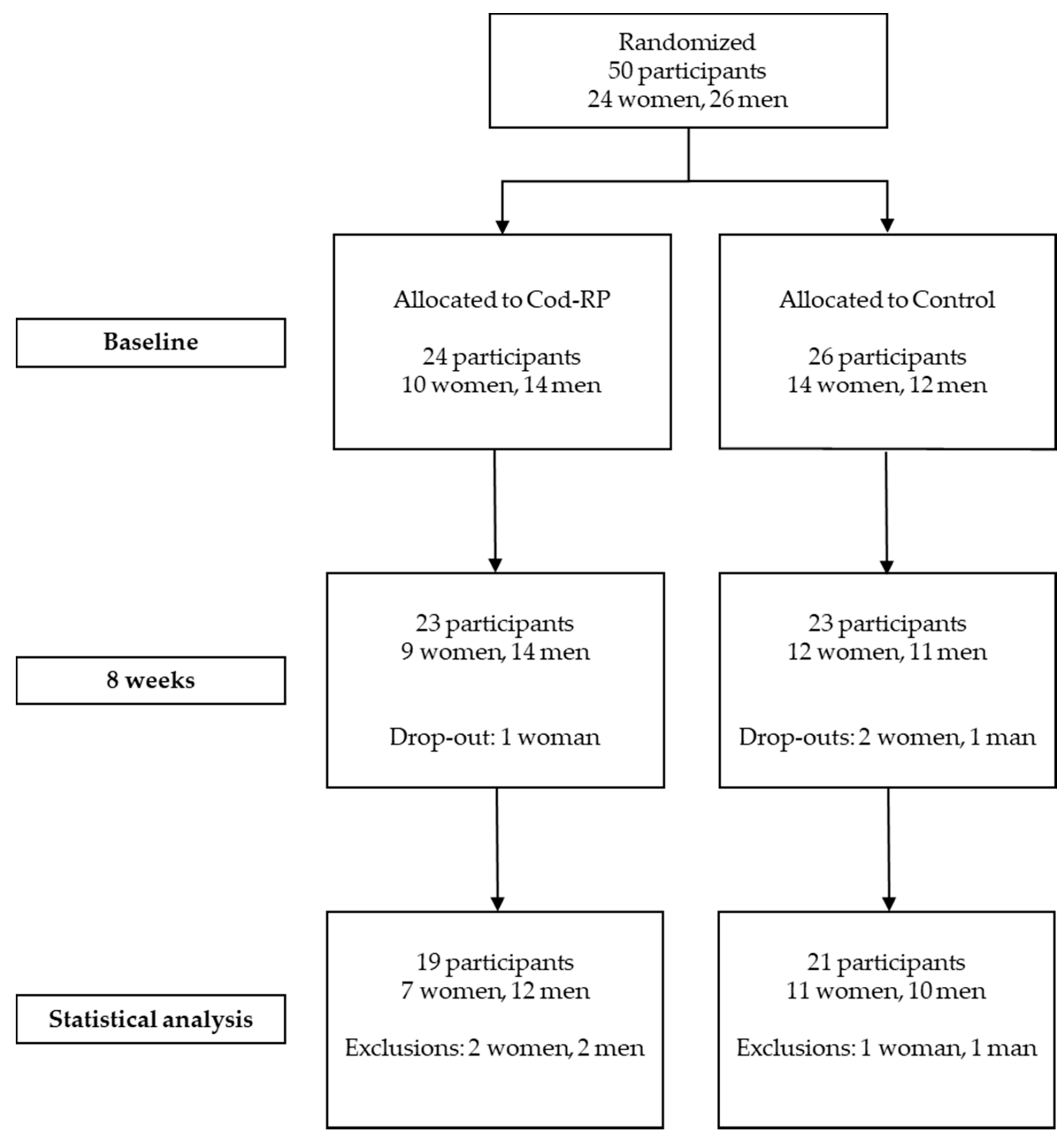

Figure 1. Flow of participants through the study. Participants could withdraw at any time and participants were excluded from analysis if they did not comply with the study protocol. Cod-RP, cod residual protein powder.

3.2. The Contents of Trimethylamine N-oxide, Anserine, Microorganisms and Heavy Metals from the Capsules

The estimated intakes of TMAO and anserine from the Cod-RP capsules were 14.4 and $7.8 \mathrm{mg} / \mathrm{day}$, respectively (average of two measurements of the capsule composition, with deviations $<5 \%$ between parallels). TMAO and anserine were not detected in the Control capsules. The contents of microorganisms in the cod residual powder were at an acceptably low level for human consumption. It was estimated that the participants' weekly intake of cadmium and mercury was equivalent to 0.08 and $0.13 \mu \mathrm{g} / \mathrm{kg}$ body weight, respectively (participants' average body weight of $75 \mathrm{~kg}$ ). The tolerable weekly intake for cadmium and mercury is 2.5 and $1.3 \mu \mathrm{g} / \mathrm{kg}$ body weight, respectively [36,37]. Thus, the estimated intake of the heavy metals cadmium and mercury from cod residual protein powder was within the tolerable weekly intake. 


\subsection{Circulating Markers Related to Glucose Regulation}

Fasting serum concentrations of glucose and insulin were unchanged in both groups from baseline to eight weeks (Figure 2). Comparison of serum glucose after OGTT at baseline, and following eight weeks of supplementation, revealed that only glucose concentration at $60 \mathrm{~min}$ decreased in the Cod-RP group compared with the Control group $(p=0.0078)$. Changes in postprandial insulin concentrations, from baseline to eight weeks, did not differ between groups at any time points. Fasting plasma concentrations of $\alpha-\mathrm{HB}, \beta-\mathrm{HB}$ and AcAc were decreased in the Cod-RP group when compared with the Control group after eight weeks of supplementation (Figure 3).

(a)

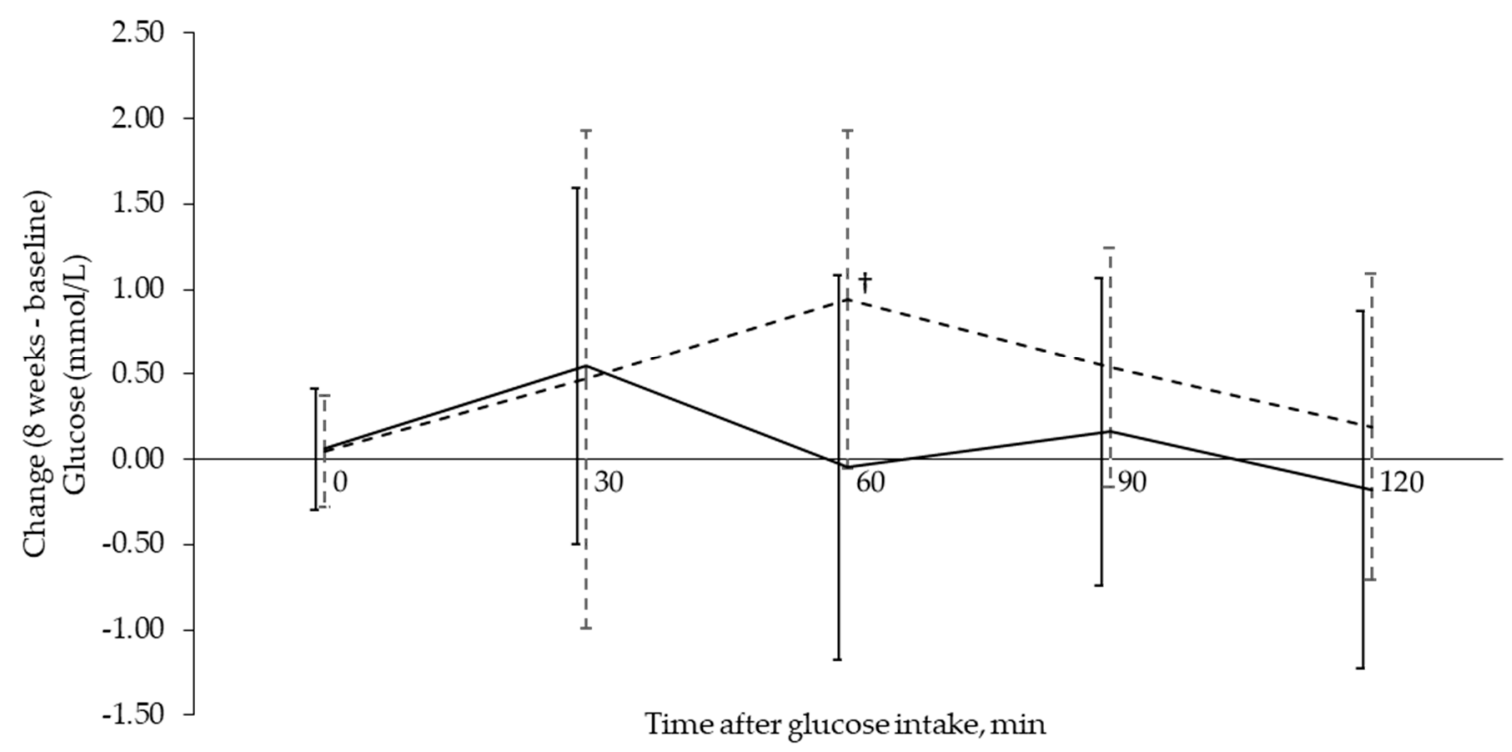

(b)

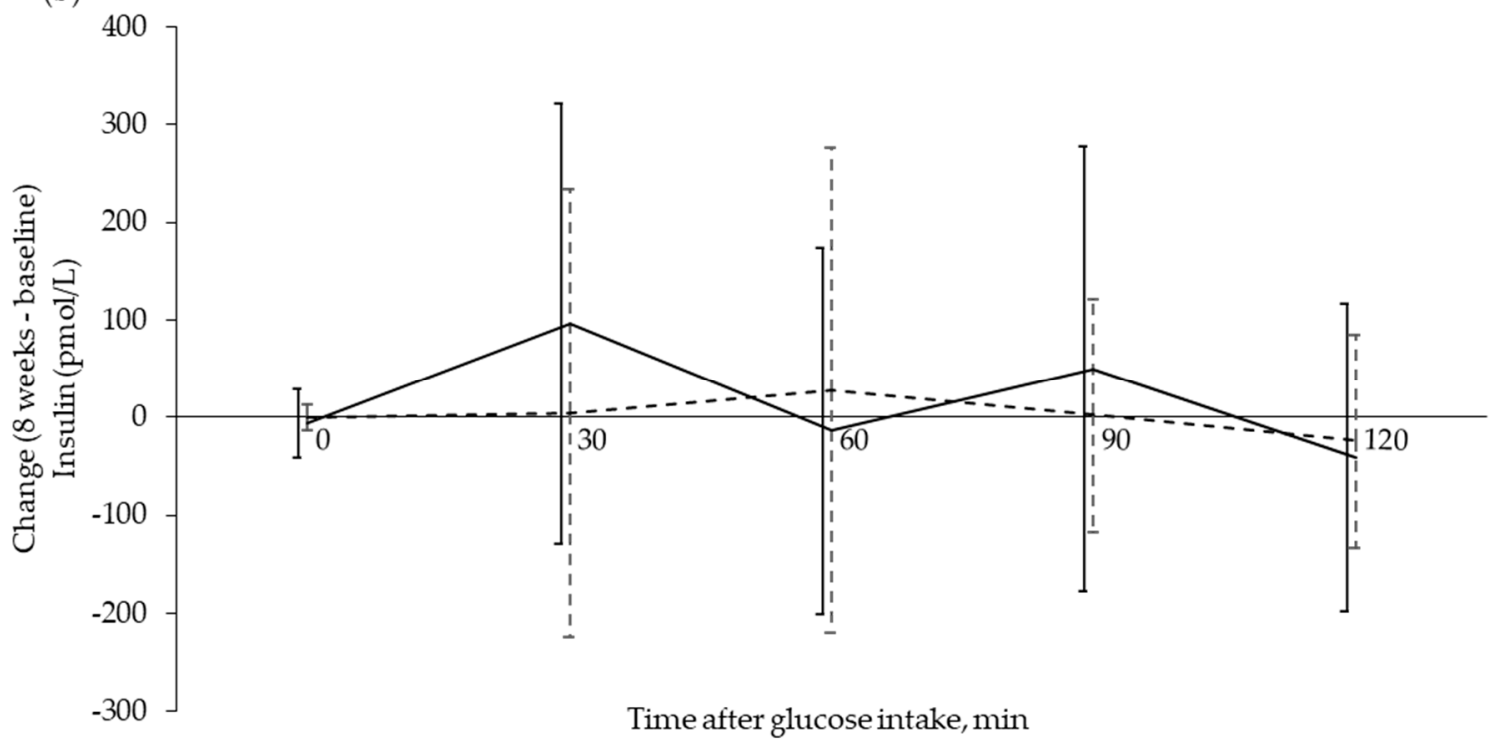

Figure 2. Glucose and insulin response during an oral glucose tolerance test (OGTT) shown as change from baseline to 8 weeks after supplementation. Glucose response (a) and insulin response (b) are expressed as change (8 weeks-baseline) in the Cod-RP (-) group and the Control group (- -), at 0 (fasting), 30, 60, 90 and $120 \mathrm{~min}$ after oral glucose intake. The results are presented as mean with standard deviation for 18 participants in the Cod-RP group and 19 participants in the Control group. + Between-group changes were compared using the independent samples $T$-test, where $p<0.05$ was considered significant. 


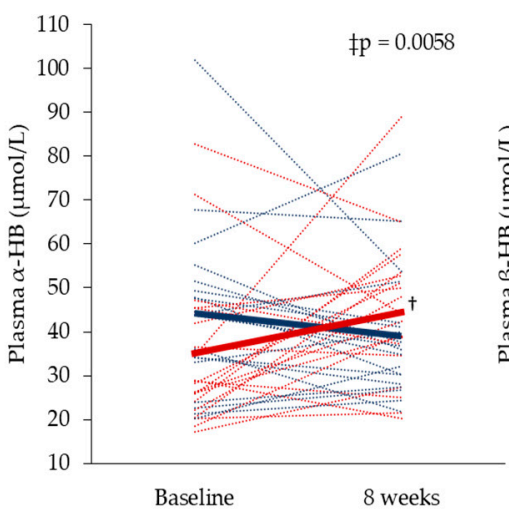

(b)

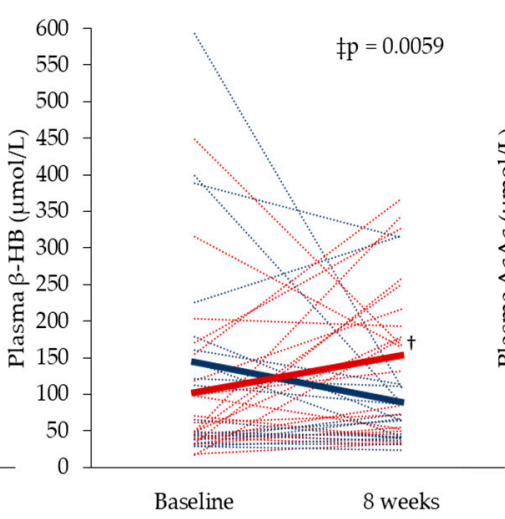

(c)

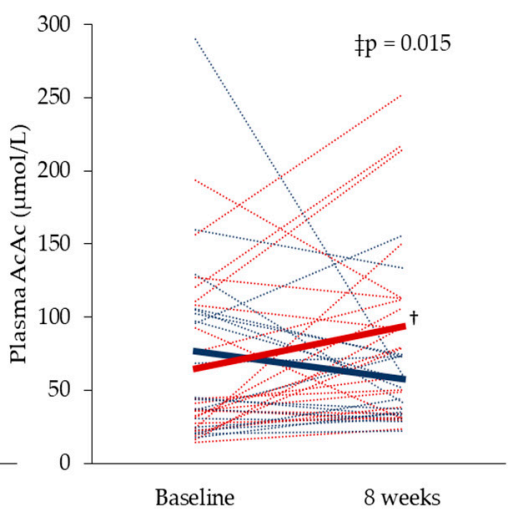

Figure 3. Fasting circulating concentrations of (a) $\alpha$-Hydroxybutyrate $(\alpha-\mathrm{HB}),(\mathbf{b}) \beta$-Hydroxybutyrate $(\beta-\mathrm{HB})$ and $(\mathrm{c})$ acetoacetate $(\mathrm{AcAc})$, at baseline and after 8 weeks of supplementation. Concentrations in the Cod-RP group are indicated by blue lines and concentrations in the Control group are indicated by red lines. The means of each group are indicated by bold lines in their respective colors. The results are presented for 19 participants in the Cod-RP group and 21 participants in the Control group. † Within-group changes were tested using the paired samples $T$-test, where $p<0.05$ was considered significant. $\ddagger$ Between-group changes were compared using the independent samples $T$-test.

\subsection{Plasma and Urine Biomarkers Related to Cod Residual Protein Intake}

Plasma and urine concentrations of TMAO were increased, whereas concentrations of creatine, 1-MeHis and 3-MeHis were unchanged in both plasma and urine in the Cod-RP group, when compared with the Control group, after eight weeks intervention (Table 3).

Table 3. Plasma and urine biomarkers related to cod residual protein intake.

\begin{tabular}{|c|c|c|c|c|}
\hline & Baseline & 8 Weeks & $p^{\dagger}$ & $p \ddagger$ \\
\hline & Mean \pm SD & Mean \pm SD & & \\
\hline \multicolumn{5}{|l|}{ Plasma $(\mu \mathrm{mol} / \mathrm{L})$} \\
\hline TMAO & & & & 0.048 \\
\hline Cod-RP group & $4.3 \pm 2.2$ & $5.8 \pm 3.3$ & 0.032 & \\
\hline Control group & $5.2 \pm 6.2$ & $4.6 \pm 6.3$ & 0.36 & \\
\hline Creatine & & & & 0.11 \\
\hline Cod-RP group & $24.9 \pm 15.3$ & $26.8 \pm 15.4$ & 0.36 & \\
\hline Control group & $32.2 \pm 18.2$ & $30.5 \pm 21.8$ & 0.17 & \\
\hline 1-MeHis & & & & 0.17 \\
\hline Cod-RP group & $13.0 \pm 11.5$ & $7.8 \pm 7.9$ & 0.16 & \\
\hline Control group & $9.2 \pm 7.2$ & $10.7 \pm 9.1$ & 0.68 & \\
\hline 3-MeHis & & & & 0.24 \\
\hline Cod-RP group & $5.1 \pm 1.3$ & $4.9 \pm 0.9$ & 0.29 & \\
\hline Control group & $4.5 \pm 1.0$ & $4.7 \pm 1.1$ & 0.29 & \\
\hline \multicolumn{5}{|c|}{ Urine ( $\mu \mathrm{mol} / \mathrm{mmol}$ creatinine) } \\
\hline TMAO & & & & 0.026 \\
\hline Cod-RP group & $44.3 \pm 22.6$ & $63.2 \pm 31.5$ & 0.016 & \\
\hline Control group & $53.3 \pm 68.3$ & $42.0 \pm 43.5$ & 0.30 & \\
\hline Creatine & & & & 0.18 \\
\hline Cod-RP group & $2.7 \pm 4.5$ & $6.6 \pm 14.9$ & 0.29 & \\
\hline Control group & $7.0 \pm 11.8$ & $5.6 \pm 11.1$ & 0.37 & \\
\hline 1-MeHis & & & & 0.49 \\
\hline Cod-RP group & $90.9 \pm 81.4$ & $54.1 \pm 54.0$ & 0.16 & \\
\hline Control group & $69.0 \pm 62.7$ & $72.1 \pm 57.9$ & 0.72 & \\
\hline
\end{tabular}


Table 3. Cont.

\begin{tabular}{ccccc}
\hline & Baseline & 8 Weeks & $p^{\dagger}$ & $p \ddagger$ \\
\hline Mean \pm SD & Mean \pm SD & & \\
\hline 3-MeHis & & & & 0.16 \\
Cod-RP group & $29.5 \pm 9.4$ & $28.2 \pm 6.5$ & 0.77 & \\
Control group & $25.1 \pm 5.6$ & $26.4 \pm 6.7$ & 0.41 & \\
\hline
\end{tabular}

Values are presented as mean \pm standard deviation for 19 participants in the Cod-RP group and 21 participants in the Control group. The level of significance was set to $<0.05 .{ }^{+}$Within-group changes were tested using paired samples $T$-test. $\ddagger$ Between-group changes were compared using the independent samples $T$-test. Plasma and urine concentrations of TMAO, creatine, 1-MeHis and 3-MiHis were similar between groups at baseline. Cod-RP, cod residual protein powder; TMAO, Trimethylamine N-oxide; 1-MeHis, 1-Methylhistidine; 3-MeHis, 3-Methylhistidine.

\section{Discussion}

In the current study, we show that eight weeks of cod residual supplementation decreased fasting plasma concentrations of $\alpha-\mathrm{HB}, \beta-\mathrm{HB}$ and AcAc, when compared to the Control group. We also observed an increase in TMAO concentration in both plasma and urine in the Cod-RP group, and propose TMAO as a biomarker of cod residual protein intake. To our knowledge, this study is the first to explore the effects of a cod residual protein supplement on glucose regulation and potential biomarkers of cod residual protein intake in lean adults.

The significant reduction in circulating $\alpha$-HB concentration in the Cod-RP group compared with the Control group suggests that cod residual supplementation may have beneficial effects on glucose regulation, as the concentration of this metabolite is shown to increase under conditions of impaired glucose tolerance $[16,17,19]$. The current study also demonstrates decreased glucose concentration 60 min after glucose intake in the Cod-RP group, from baseline to eight weeks, compared with the Control group, however, postprandial measurements 30,90 and 120 min did not differ between the two groups. Previous studies have observed that intake of proteins from cod fillet or cod residuals may improve postprandial glucose regulation in overweight adults and in obese rats, with no effects on fasting serum concentrations of glucose or insulin [12-14,38]. In line with this, two clinical studies, investigating the effects of $750 \mathrm{~g}$ cod fillet per week in normal-weight adults for four weeks [39], or overweight adults for eight weeks [40], did not find beneficial effects on fasting glucose and insulin concentrations. In the present study cohort, fasting non-esterified fatty acid (NEFA) concentration decreased after Cod-RP supplementation when compared with Control [21], which could be tied to the decrease in $\alpha$-HB $[16,17,19] . \alpha$-HB is synthesized in the liver from $\alpha$-ketobutyrate, which is a substrate for pyruvate dehydrogenase. The pyruvate dehydrogenase activity is indirectly inhibited by increased NEFA concentration [41,42], resulting in more $\alpha$-ketobutyrate available for $\alpha$-HB production. The mechanisms underlying the observations in the present study are currently unknown, but based on the pattern of changes, we speculate that the decreased $\alpha-\mathrm{HB}$ in the Cod-RP group may be associated with the decrease in circulating NEFA. This is further supported by the decreased concentrations of the ketone bodies $\beta-\mathrm{HB}$ and AcAc in the Cod-RP group, since these are products of NEFA oxidation, and high circulating concentrations of ketone bodies have been associated with impaired glucose tolerance [18]. The decreases in $\alpha-\mathrm{HB}, \beta-\mathrm{HB}$ and AcAc suggest that Cod-RP supplementation increased glucose utilization, despite not affecting fasting concentrations of serum glucose and insulin in this healthy cohort.

The increased TMAO concentrations in both plasma and urine in the Cod-RP group is in agreement with studies demonstrating increased urine or plasma/serum TMAO concentrations after cod fillet intake [23-25,27]. Indeed, higher urinary TMAO concentrations have been observed in populations with high fish intake, when compared to populations with low fish intake [30,31]. TMAO concentration in plasma and urine have also been shown to increase after intake of foods other than fish, if containing precursors of TMAO [25,26,43], but not to the same extent as after fish intake [25-27,44]. Circulating TMAO concentration may increase when kidney function is decreased [45], however, all participants in the current study had normal kidney function, as indicated by normal urine albumin concentration 
(relative to creatinine) and normal plasma creatinine concentration. Therefore, the increased plasma TMAO concentrations in the Cod-RP group were most likely a result of TMAO intake from the Cod-RP supplements, and not a consequence of impaired kidney function. Following Cod-RP supplementation in the present study, the increased TMAO concentration was more pronounced in urine than in plasma. This is in line with a study demonstrating increased concentrations of TMAO in serum, and particularly in urine, among overweight adults after consumption of $750 \mathrm{~g} /$ week of cod fillet for eight weeks [24]. Therefore, this work further suggests that TMAO measured in urine and plasma may be a reliable biomarker of cod intake, and should be measured in future studies assessing compliance to cod residual protein intake.

We found no changes in plasma and urine concentrations of 1-MeHis, 3-MeHis and creatine after Cod-RP supplementation. The concentrations of these biomarkers have been shown to increase after intake of meat [46-49], which was part of the participants' habitual dietary intake. This could explain why no differences in the concentrations of 1-MeHis, 3-MeHis and creatine were observed after Cod-RP supplementation, when compared with Control supplementation. However, cod fillet consumption (750 g/week for eight weeks) increased both serum and urine creatine, and 1-MeHis concentrations, compared with meat intake in overweight adults [24]. These contradictory findings may be attributed to a higher intake of creatine and 1-MeHis from consuming $750 \mathrm{~g} /$ week of cod fillet, compared with only $57 \mathrm{~g} /$ week of cod residual protein in the current study.

The present study has some limitations. The decreases in circulating concentrations of metabolites related to glucose regulation in the current intervention were observed among lean adults, and may not be translatable to individuals at risk of developing type 2 diabetes or cardiovascular disease. Further exploration of changes in concentrations of $\alpha-\mathrm{HB}, \beta-\mathrm{HB}$ and AcAc after cod residual protein intake in individuals with impaired glucose tolerance is therefore suggested.

\section{Conclusions}

To conclude, eight weeks of supplementation with cod residual proteins lowered plasma concentrations of the early markers of impaired glucose regulation $\alpha-\mathrm{HB}, \beta-\mathrm{HB}$ and AcAc, when compared to the Control group, thus suggesting that cod residual proteins may beneficially affect glucose regulation. TMAO concentrations in plasma, and particularly in urine, were increased after cod residual protein supplementation, indicating that TMAO could be a relevant biomarker of cod residual protein intake.

Author Contributions: Conceptualization, I.V., A.H., Å.O. and O.A.G.; Methodology, validation, formal analysis, investigation, I.V., A.M., Ø.M., P.M.U. and O.A.G.; Data curation and writing-original draft preparation, I.V.; Writing-review and editing, I.V., A.H., A.M., Ø.M., P.M.U., Å.O. and O.A.G. All authors have read and agreed to the published version of the manuscript.

Funding: This research was funded by The Research Council of Norway (project no. 252540); K. Halstensen AS and the Regional Research Fund Western Norway.

Acknowledgments: We thank Ingmar Høgøy from Blue Protein (Storebø, Norway) for his significant contribution in the design and pre-production of the intervention capsules and Jørgen Borthen (Norwegian Seafood Center) for organizing and facilitating applications for funding and implementation of the study. The authors wish to thank all participants who have contributed to the study.

Conflicts of Interest: Iselin Vildmyren was employed as an industrial Ph.D.-Candidate at K. Halstensen AS in cooperation with the Research Council of Norway in affiliation with the University of Bergen when the current study was conducted. Alfred Halstensen is shareholder in K. Halstensen AS. The other authors declare no conflict of interest. The funders had no role in the design of the study; in the collection, analyses, or interpretation of data; in the writing of the manuscript, or in the decision to publish the results.

\section{References}

1. Kromhout, D.; Bosschieter, E.B.; de Lezenne Coulander, C. The inverse relation between fish consumption and 20-year mortality from coronary heart disease. N. Engl. J. Med. 1985, 312, 1205-1209. [CrossRef] [PubMed] 
2. Nkondjock, A.; Receveur, O. Fish-seafood consumption, obesity, and risk of type 2 diabetes: An ecological study. Diabetes Metab. 2003, 29, 635-642. [CrossRef]

3. Virtanen, J.K.; Mozaffarian, D.; Chiuve, S.E.; Rimm, E.B. Fish consumption and risk of major chronic disease in men. Am. J. Clin. Nutr. 2008, 88, 1618-1625. [CrossRef] [PubMed]

4. Zheng, J.; Huang, T.; Yu, Y.; Hu, X.; Yang, B.; Li, D. Fish consumption and chd mortality: An updated meta-analysis of seventeen cohort studies. Public Health Nutr. 2012, 15, 725-737. [CrossRef] [PubMed]

5. Zhou, Y.; Tian, C.; Jia, C. Association of fish and n-3 fatty acid intake with the risk of type 2 diabetes: A meta-analysis of prospective studies. Br. J. Nutr. 2012, 108, 408-417. [CrossRef] [PubMed]

6. Chowdhury, R.; Stevens, S.; Gorman, D.; Pan, A.; Warnakula, S.; Chowdhury, S.; Ward, H.; Johnson, L.; Crowe, F.; Hu, F.B.; et al. Association between fish consumption, long chain omega 3 fatty acids, and risk of cerebrovascular disease: Systematic review and meta-analysis. Bmj 2012, 345, e6698. [CrossRef]

7. Alhassan, A.; Young, J.; Lean, M.E.J.; Lara, J. Consumption of fish and vascular risk factors: A systematic review and meta-analysis of intervention studies. Atherosclerosis 2017, 266, 87-94. [CrossRef]

8. Mozaffarian, D.; Wu, J.H. Omega-3 fatty acids and cardiovascular disease: Effects on risk factors, molecular pathways, and clinical events. J. Am. Coll. Cardiol. 2011, 58, 2047-2067. [CrossRef]

9. Feskens, E.J.; Bowles, C.H.; Kromhout, D. Inverse association between fish intake and risk of glucose intolerance in normoglycemic elderly men and women. Diabetes Care 1991, 14, 935-941. [CrossRef]

10. Lavigne, C.; Tremblay, F.; Asselin, G.; Jacques, H.; Marette, A. Prevention of skeletal muscle insulin resistance by dietary cod protein in high fat-fed rats. Am. J. Physiol. Endocrinol. Metab. 2001, 281, E62-E71. [CrossRef]

11. Ouellet, V.; Marois, J.; Weisnagel, S.J.; Jacques, H. Dietary cod protein improves insulin sensitivity in insulin-resistant men and women: A randomized controlled trial. Diabetes Care 2007, 30, 2816-2821. [CrossRef] [PubMed]

12. Vikoren, L.A.; Nygard, O.K.; Lied, E.; Rostrup, E.; Gudbrandsen, O.A. A randomised study on the effects of fish protein supplement on glucose tolerance, lipids and body composition in overweight adults. Br. J. Nutr. 2013, 109, 648-657. [CrossRef] [PubMed]

13. Drotningsvik, A.; Mjos, S.A.; Hogoy, I.; Remman, T.; Gudbrandsen, O.A. A low dietary intake of cod protein is sufficient to increase growth, improve serum and tissue fatty acid compositions, and lower serum postprandial glucose and fasting non-esterified fatty acid concentrations in obese zucker fa/fa rats. Eur. J. Nutr. 2015, 54, 1151-1160. [CrossRef] [PubMed]

14. Vildmyren, I.; Cao, H.J.V.; Haug, L.B.; Valand, I.U.; Eng, O.; Oterhals, A.; Austgulen, M.H.; Halstensen, A.; Mellgren, G.; Gudbrandsen, O.A. Daily intake of protein from cod residual material lowers serum concentrations of nonesterified fatty acids in overweight healthy adults: A randomized double-blind pilot study. Mar. Drugs 2018, 16, 197. [CrossRef]

15. Lavigne, C.; Marette, A.; Jacques, H. Cod and soy proteins compared with casein improve glucose tolerance and insulin sensitivity in rats. Am. J. Physiol. Endocrinol. Metab. 2000, 278, E491-E500. [CrossRef] [PubMed]

16. Gall, W.E.; Beebe, K.; Lawton, K.A.; Adam, K.P.; Mitchell, M.W.; Nakhle, P.J.; Ryals, J.A.; Milburn, M.V.; Nannipieri, M.; Camastra, S.; et al. Alpha-hydroxybutyrate is an early biomarker of insulin resistance and glucose intolerance in a nondiabetic population. PLoS ONE 2010, 5, e10883. [CrossRef]

17. Ferrannini, E.; Natali, A.; Camastra, S.; Nannipieri, M.; Mari, A.; Adam, K.P.; Milburn, M.V.; Kastenmuller, G.; Adamski, J.; Tuomi, T.; et al. Early metabolic markers of the development of dysglycemia and type 2 diabetes and their physiological significance. Diabetes 2013, 62, 1730-1737. [CrossRef]

18. Mahendran, Y.; Vangipurapu, J.; Cederberg, H.; Stancakova, A.; Pihlajamaki, J.; Soininen, P.; Kangas, A.J.; Paananen, J.; Civelek, M.; Saleem, N.K.; et al. Association of ketone body levels with hyperglycemia and type 2 diabetes in 9,398 finnish men. Diabetes 2013, 62, 3618-3626. [CrossRef]

19. Cobb, J.; Eckhart, A.; Motsinger-Reif, A.; Carr, B.; Groop, L.; Ferrannini, E. Alpha-hydroxybutyric acid is a selective metabolite biomarker of impaired glucose tolerance. Diabetes Care 2016, 39, 988-995. [CrossRef]

20. Richardsen, R.; Nystøyl, R.; Strandheim, G.; Marthinussen, A. Report: Analysis of marine residual raw material. SINTEF 2016.

21. Vildmyren, I.; Halstensen, A.; Oterhals, A.; Gudbrandsen, O.A. Cod protein powder lowered serum nonesterified fatty acids and increased total bile acid concentrations in healthy, lean, physically active adults: A randomized double-blind study. Food Nutr. Res. 2019, 63. [CrossRef] 
22. Subar, A.F.; Kipnis, V.; Troiano, R.P.; Midthune, D.; Schoeller, D.A.; Bingham, S.; Sharbaugh, C.O.; Trabulsi, J.; Runswick, S.; Ballard-Barbash, R.; et al. Using intake biomarkers to evaluate the extent of dietary misreporting in a large sample of adults: The open study. Am. J. Epidemiol. 2003, 158,1-13. [CrossRef] [PubMed]

23. Drotningsvik, A.; Midttun, O.; McCann, A.; Ueland, P.M.; Hogoy, I.; Gudbrandsen, O.A. Dietary intake of cod protein beneficially affects concentrations of urinary markers of kidney function and results in lower urinary loss of amino acids in obese zucker fa/fa rats. Br. J. Nutr. 2018, 120, 740-750. [CrossRef] [PubMed]

24. Hagen, I.V.; Helland, A.; Bratlie, M.; Midttun, O.; McCann, A.; Sveier, H.; Rosenlund, G.; Mellgren, G.; Ueland, P.M.; Gudbrandsen, O.A. Tmao, creatine and 1-methylhistidine in serum and urine are potential biomarkers of cod and salmon intake: A randomised clinical trial in adults with overweight or obesity. Eur. J. Nutr. 2019, 1-11. [CrossRef] [PubMed]

25. Cho, C.E.; Taesuwan, S.; Malysheva, O.V.; Bender, E.; Tulchinsky, N.F.; Yan, J.; Sutter, J.L.; Caudill, M.A. Trimethylamine-n-oxide (tmao) response to animal source foods varies among healthy young men and is influenced by their gut microbiota composition: A randomized controlled trial. Mol. Nutr. Food Res. 2017, 61, 1600324. [CrossRef]

26. Cheung, W.; Keski-Rahkonen, P.; Assi, N.; Ferrari, P.; Freisling, H.; Rinaldi, S.; Slimani, N.; Zamora-Ros, R.; Rundle, M.; Frost, G.; et al. A metabolomic study of biomarkers of meat and fish intake. Am. J. Clin. Nutr. 2017, 105, 600-608. [CrossRef]

27. Schmedes, M.; Balderas, C.; Aadland, E.K.; Jacques, H.; Lavigne, C.; Graff, I.E.; Eng, O.; Holthe, A.; Mellgren, G.; Young, J.F.; et al. The effect of lean-seafood and non-seafood diets on fasting and postprandial serum metabolites and lipid species: Results from a randomized crossover intervention study in healthy adults. Nutrients 2018, 10, 598. [CrossRef]

28. Sjolin, J.; Hjort, G.; Friman, G.; Hambraeus, L. Urinary excretion of 1-methylhistidine: A qualitative indicator of exogenous 3-methylhistidine and intake of meats from various sources. Metabolism 1987, 36, 1175-1184. [CrossRef]

29. Drotningsvik, A.; Pampanin, D.M.; Slizyte, R.; Carvajal, A.; Hogoy, I.; Remman, T.; Gudbrandsen, O.A. Hydrolyzed proteins from herring and salmon rest raw material contain peptide motifs with angiotensin-i converting enzyme inhibitors and resulted in lower urine concentrations of protein, cystatin c and glucose when fed to obese zucker fa/fa rats. Nutr. Res. 2018, 52, 14-21. [CrossRef]

30. Lenz, E.M.; Bright, J.; Wilson, I.D.; Hughes, A.; Morrisson, J.; Lindberg, H.; Lockton, A. Metabonomics, dietary influences and cultural differences: A $1 \mathrm{~h}$ nmr-based study of urine samples obtained from healthy british and swedish subjects. J. Pharm. Biomed. Anal. 2004, 36, 841-849. [CrossRef]

31. Dumas, M.E.; Maibaum, E.C.; Teague, C.; Ueshima, H.; Zhou, B.; Lindon, J.C.; Nicholson, J.K.; Stamler, J.; Elliott, P.; Chan, Q.; et al. Assessment of analytical reproducibility of $1 \mathrm{~h} \mathrm{nmr}$ spectroscopy based metabonomics for large-scale epidemiological research: The intermap study. Anal. Chem. 2006, 78, 2199-2208. [CrossRef] [PubMed]

32. Conway, E.J. An absorption apparatus for the micro-determination of certain volatile substances: The determination of urea and ammonia in body fluids. Biochem. J. 1933, 27, 430-434. [PubMed]

33. Bidlingmeyer, B.A.; Cohen, S.A.; Tarvin, T.L.; Frost, B. A new, rapid, high-sensitivity analysis of amino acids in food type samples. J. Assoc. Off. Anal. Chem. 1987, 70, 241-247. [CrossRef] [PubMed]

34. Midttun, O.; McCann, A.; Aarseth, O.; Krokeide, M.; Kvalheim, G.; Meyer, K.; Ueland, P.M. Combined measurement of 6 fat-soluble vitamins and 26 water-soluble functional vitamin markers and amino acids in 50 mul of serum or plasma by high-throughput mass spectrometry. Anal. Chem. 2016, 88, 10427-10436. [CrossRef]

35. Midttun, O.; Kvalheim, G.; Ueland, P.M. High-throughput, low-volume, multianalyte quantification of plasma metabolites related to one-carbon metabolism using hplc-ms/ms. Anal. Bioanal. Chem. 2013, 405, 2009-2017. [CrossRef]

36. Chain, E.P.o.C.i.t.F. Statement on tolerable weekly intake for cadmium. EFSA J. 2011, 9, 1975.

37. Chain, E.P.o.C.i.t.F. Scientific opinion on the risk for public health related to the presence of mercury and methylmercury in food. EFSA J. 2012, 10, 2985.

38. Hovland, I.H.; Leikanger, I.S.; Stokkeland, O.; Waage, K.H.; Mjos, S.A.; Brokstad, K.A.; McCann, A.; Ueland, P.M.; Slizyte, R.; Carvajal, A.; et al. Effects of low doses of fish and milk proteins on glucose regulation and markers of insulin sensitivity in overweight adults: A randomised, double blind study. Eur. J. Nutr. 2019, 1-17. [CrossRef] 
39. Hagen, I.V.; Helland, A.; Bratlie, M.; Brokstad, K.A.; Rosenlund, G.; Sveier, H.; Mellgren, G.; Gudbrandsen, O.A. High intake of fatty fish, but not of lean fish, affects serum concentrations of tag and hdl-cholesterol in healthy, normal-weight adults: A randomised trial. Br. J. Nutr. 2016, 116, 648-657. [CrossRef]

40. Helland, A.; Bratlie, M.; Hagen, I.V.; Mjos, S.A.; Sornes, S.; Halstensen, A.I.; Brokstad, K.A.; Sveier, H.; Rosenlund, G.; Mellgren, G.; et al. High intake of fatty fish, but not of lean fish, improved postprandial glucose regulation and increased the $\mathrm{n}-3$ pufa content in the leucocyte membrane in healthy overweight adults: A randomised trial. Br. J. Nutr. 2017, 117, 1368-1378. [CrossRef]

41. Zhang, S.; Hulver, M.W.; McMillan, R.P.; Cline, M.A.; Gilbert, E.R. The pivotal role of pyruvate dehydrogenase kinases in metabolic flexibility. Nutr. Metab. 2014, 11, 10. [CrossRef] [PubMed]

42. Wu, P.; Inskeep, K.; Bowker-Kinley, M.M.; Popov, K.M.; Harris, R.A. Mechanism responsible for inactivation of skeletal muscle pyruvate dehydrogenase complex in starvation and diabetes. Diabetes 1999, 48, 1593-1599. [CrossRef] [PubMed]

43. Koeth, R.A.; Wang, Z.; Levison, B.S.; Buffa, J.A.; Org, E.; Sheehy, B.T.; Britt, E.B.; Fu, X.; Wu, Y.; Li, L.; et al. Intestinal microbiota metabolism of l-carnitine, a nutrient in red meat, promotes atherosclerosis. Nat. Med. 2013, 19, 576-585. [CrossRef] [PubMed]

44. Zhang, A.Q.; Mitchell, S.C.; Smith, R.L. Dietary precursors of trimethylamine in man: A pilot study. Food Chem. Toxicol. 1999, 37, 515-520. [CrossRef]

45. Zeisel, S.H.; Warrier, M. Trimethylamine n-oxide, the microbiome, and heart and kidney disease. Annu. Rev. Nutr. 2017, 37, 157-181. [CrossRef] [PubMed]

46. Myint, T.; Fraser, G.E.; Lindsted, K.D.; Knutsen, S.F.; Hubbard, R.W.; Bennett, H.W. Urinary 1-methylhistidine is a marker of meat consumption in black and in white california seventh-day adventists. Am. J. Epidemiol. 2000, 152, 752-755. [CrossRef] [PubMed]

47. Dragsted, L.O. Biomarkers of meat intake and the application of nutrigenomics. Meat Sci. 2010, 84, 301-307. [CrossRef]

48. Cross, A.J.; Major, J.M.; Sinha, R. Urinary biomarkers of meat consumption. Cancer Epidemiol. Biomarkers Prev. 2011, 20, 1107-1111. [CrossRef]

49. Altorf-van der Kuil, W.; Brink, E.J.; Boetje, M.; Siebelink, E.; Bijlsma, S.; Engberink, M.F.; van ‘t Veer, P.; Tome, D.; Bakker, S.J.; van Baak, M.A.; et al. Identification of biomarkers for intake of protein from meat, dairy products and grains: A controlled dietary intervention study. Br. J. Nutr. 2013, 110, 810-822. [CrossRef] 